\section{Heat Transfer at the Bottom of a Cylindrical Vessel Impinged by a Swirling Flow from an Impeller in a Draft Tube}

\author{
K. Petera, " M. Dostál, M. Věříšová, and T. Jirout \\ Czech Technical University in Prague, Faculty of Mechanical \\ Engineering, Department of Process Engineering, \\ Technicka 4, 16607 Prague, Czech Republic
}

doi: 10.15255/CABEQ.2016.1057

Original scientific paper

Received: December 21, 2016

Accepted: July 28, 2017

\begin{abstract}
Heat transfer at the bottom of a cylindrical vessel impinged by a flow with tangential velocity component generated by an axial-flow impeller in a draft tube was measured using the electrodiffusion experimental method. Local values of the Nusselt numbers along the radial coordinate of the heat transfer surface and corresponding mean values are presented for relatively small distances of the draft tube from the impinged surface $(0.25 \leq h / d \leq 1)$. Such small distances are typical for mixing of liquids, which ensures good homogenization and increases the intensity of heat and mass transfer in many industrial operations. Results are compared with literature data for unconfined impinging jets with no tangential velocity components. The additional tangential velocity component generated by the rotating impeller significantly influences the hydrodynamics of the impinging jet and decreases the heat transfer intensity in the case of small distances from the impinged surface. A correlation describing the mean Nusselt number at the vessel bottom is proposed. It can be used in a design of a real industrial piece of equipment with heat transfer situated at the bottom.
\end{abstract}

Key words:

heat transfer, impinging jet, swirling flow, mixing vessel

\section{Introduction}

Impinging jets are frequently used in cooling of electronic components as well as in cooling or heating processes which are part of many industrial equipment. A stream of fluid leaving a jet (of various shapes and configurations) impacts a surface in normal direction usually, and provides high transfer rates and the possibility to delimit the heat transfer surface accurately. A stream of liquid generated by an axial-flow impeller in an agitated vessel impacts the vessel bottom similarly as the stream of fluid leaving a round jet and impinging a plane surface. Some similarities should exist here, the main difference lies in the tangential velocity component generated by the rotating impeller and that the jet is confined by the vessel walls. Mixing of liquids by mechanical impellers, for example an axial-flow impeller accompanied by a draft tube, see Figure 1, belongs to a large group of industrial processes which ensures good homogenization of liquid in a system, and increases the intensity of heat and mass transfer. The heat exchange surface is frequently located at the bottom of the vessel, and determining the heat transfer intensity is very important in prediction of the heating or cooling time.

"Corresponding author: karel.petera@fs.cvut.cz
This paper is focused on heat transfer at the bottom of a cylindrical vessel where the impinging jet is generated by an axial-flow impeller placed in a draft tube. In this case, the impinged surface is confined by the vertical walls of the vessel, and a tangential (swirling) velocity component is superposed on the axial stream of the liquid leaving the draft tube. The influence of this tangential velocity component on the heat transfer at the vessel bottom, and a dimensionless correlation for the Nusselt number are presented in this paper. The tangential velocity component has a strong impact on the heat transfer, particularly in the stagnation area. Figure 1 shows a typical axial velocity profile at the outlet of the draft tube determined in CFD simulations for this geometry by Vlček and Jirout ${ }^{1}$. It differs significantly from a typical developed velocity profile in a classical impinging jet. Due to the tangential velocity component superposed to the main axial flow and consequent centrifugal forces, the maximum of the velocity profile moves away from the center. This may result in a substantial decrease in the heat transfer near the stagnation point.

Numerous experimental as well as theoretical or numerical studies of heat transfer in an unconfined impinging jet can be found in the literature, but most are devoted to non-swirling flows. Martin ${ }^{2}$ 


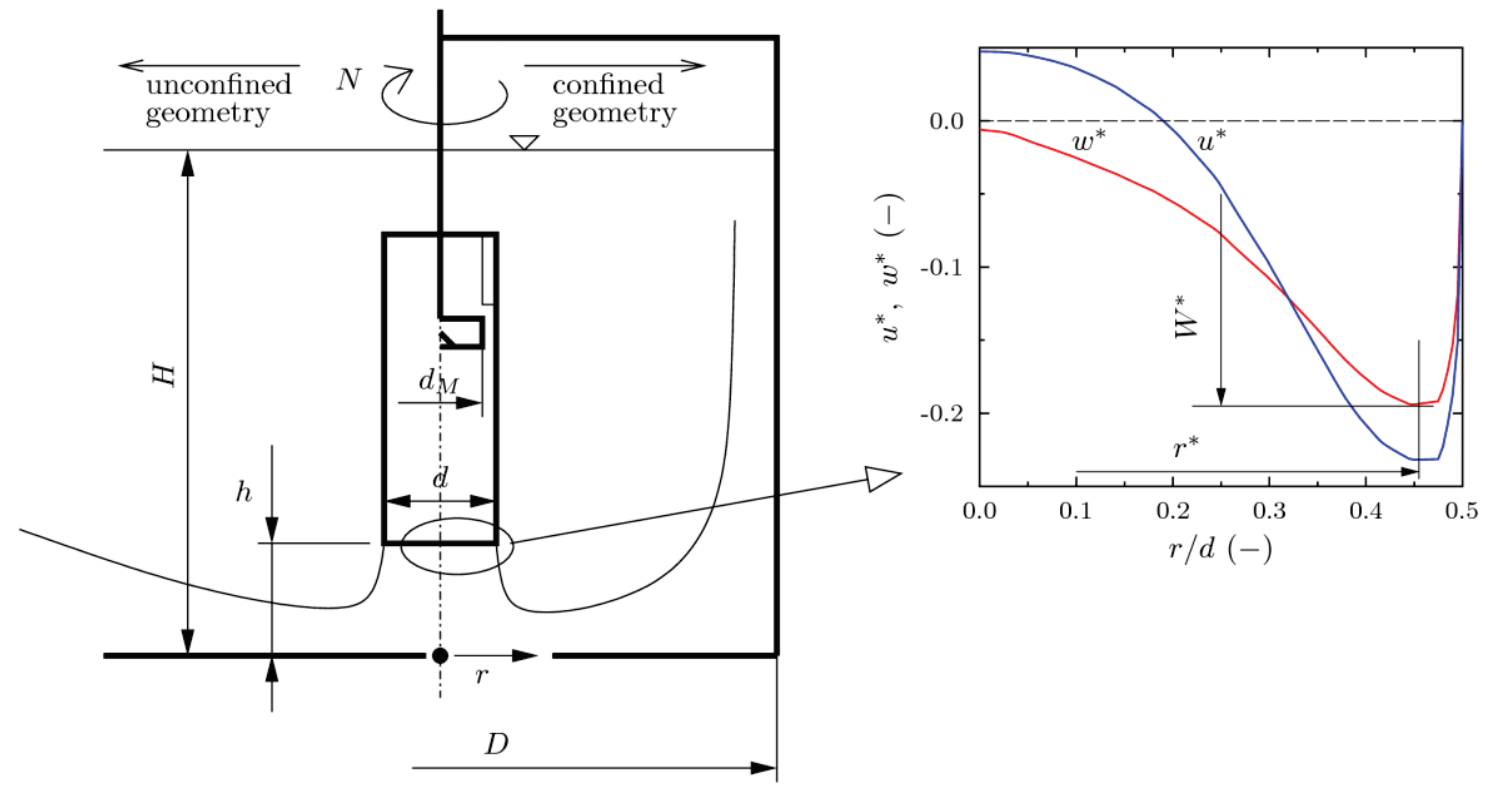

Fig. 1 - Geometrical configuration of the studied confined impinging jet generated by an axial-flow impeller in a draft tube. Example of typical axial and tangential velocity profiles at the outlet of the draft tube is depicted on the right ${ }^{1}$.

published an overall review of heat and mass transfer in a jet of gas impinging a solid wall. The results were mainly focused on cases with single round or slot nozzles and their arrays. The hydrodynamics and flow patterns in the basic regions of the impinging jet - free jet zone, stagnation flow zone and wall jet zone - were briefly described there. Dependencies of local heat and mass transfer quantities in terms of the Nusselt and Sherwood numbers along the impinged plate and corresponding mean values were presented graphically and using dimensionless correlations. The influence of geometrical parameters of the nozzle as well as other parameters like turbulence promoters, shape of the surface, and angle of impact was mentioned. Concerning the swirling jets, Martin ${ }^{2}$ mentioned that the heat transfer within the stagnation region may be considerably enhanced. On the other hand, he pointed out that in certain cases the secondary peaks may vanish, and the integral mean values over a larger area were found to be even lower without turbulence promoters and the insertion of swirl baffles had no significant influence on the heat and mass transfer.

Most of the authors focused on cases where the distance of the jet nozzle from the impinged surface was a multiple of the nozzle diameter. Only a few papers deal with smaller distances around or below $h / d=1$. For example, Lytle and Webb ${ }^{3,4}$ measured local values of heat transfer for $h / d>0.1$ and Reynolds numbers above 3600 using the infrared thermography. They presented graphical dependencies of local values of the Nusselt number along the radial coordinate of the impinged plate, see Figure 2.
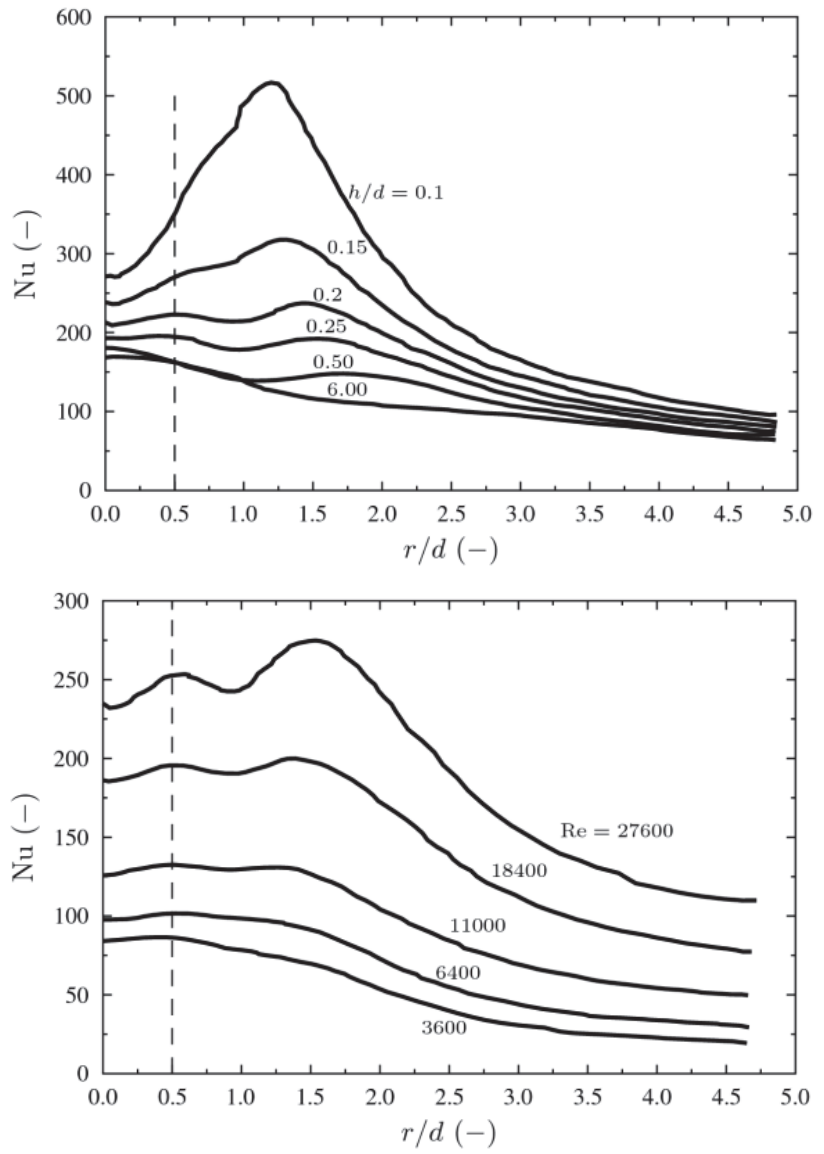

Fig. 2 - Local values of the Nusselt number with respect to the dimensionless radial coordinate for various distances and Reynolds numbers ${ }^{3,4}$

The correlation describing the Nusselt number at the stagnant point as a function of the Reynolds number with exponent 0.53 and relative distance $h / d$ 
with exponent -0.191 was proposed for air, that is for the Prandtl number $\operatorname{Pr}>0.71,3700 \leq \mathrm{Re} \leq 30000$ and for dimensionless distance $h / d \leq 1$. The correlation was reported to represent the data with average and maximum errors of $5 \%$ and $21 \%$, respectively.

Lytle and $\mathrm{Webb}^{4}$ published the following correlations for the mean value of the Nusselt number in the stagnation region (for two radial coordinate ranges $0 \leq r / d \leq 1,0 \leq r / d \leq 2)$.

$$
\begin{aligned}
& \overline{\mathrm{Nu}}_{0 \leq r / d \leq 1}=0.424 \operatorname{Re}^{0.57}\left(\frac{h}{d}\right)^{-0.33} ; \\
& \overline{\mathrm{Nu}}_{0 \leq r / d \leq 2}=0.150 \operatorname{Re}^{0.67}\left(\frac{h}{d}\right)^{-0.36}
\end{aligned}
$$

with average error estimated up to $9 \%$, and maximum error up to $29 \%$.

Viskanta $^{5}$ published another review of heat transfer in a gas jet (and flame jet). He mentioned that thickness of the impingement zone boundary layer is approximately constant and that the wall jet region is characterized by a bulk flow in the outward radial direction, and the velocity maximum occurs at approximately one jet diameter from the impingement zone for the relative nozzle-to-impingement surface distance within the range $0<h / d<12$. He also stated that the impinging jet is considered to be laminar up to a single jet Reynolds number of approximately 2500 , and four characteristic regions for circular free jets exist there: the dissipated laminar jet $\operatorname{Re}<300$, a fully laminar jet $300<\operatorname{Re}<1000$, a transition or semiturbulent jet $1000<\operatorname{Re}<3000$, and finally a fully turbulent jet for $\mathrm{Re}>3000$. Viskanta ${ }^{5}$ presented correlations and graphical dependencies of heat transfer in the stagnation point, but more focus was put on the description of the mean value of the Nusselt number at the impinged surface and influence of other parameters (nozzle diameter, angle of incidence, curvature and other factors, such as swirls, small amplitude pressure perturbations, etc.).

Sun et al. ${ }^{6}$ investigated experimentally the heat transfer between submerged impinging circular jet and small vertical heat transfer surface for seven working fluids covering a large range of the Prandtl number (air, nitrogen gas, water, R113, kerosene, ethylene glycol and transformer oil), and Reynolds number range $117-36900$. According to their literature research, the Prandtl number dependency of impingement heat transfer can be expressed by the power function of the Prandtl number itself. Various values of the Prandtl power (exponent) including the most frequently used values 0.4 and $1 / 3$, but also other values like 0.24 or 0.487 , can be seen. They evaluated the powers of the Prandtl and Reynolds numbers in the standard power correlation as
0.342 and 0.486 , respectively, on the basis of measurements in the stagnation point (169 experimental points). For these power values, $91.4 \%$ of the measured data points were within $\pm 20 \%$ interval. They concluded that it seems reasonable to have two different values of the power of Prandtl number for larger and smaller Prandtl numbers. After thoroughly checking the Prandtl number dependency with the present experimental results of the seven working fluids, they proposed the power values as 0.4 for gases and $1 / 3$ for liquids. The authors also measured the influence of the nozzle-to-plate spacing using five different experimental liquids and the radial dependency of the local heat transfer coefficient described by semi-empirical models.

Katti and $\mathrm{Prabhu}^{7}$ measured the intensity of heat transfer at a surface impinged by the stream of air leaving a circular nozzle. The infrared thermal imaging technique was used to evaluate the heat transfer coefficients at a flat plate heated by Joule's heat (constant heat flux). Their experimental results for Reynolds numbers $12000 \leq \mathrm{Re} \leq 28000$ and relatively large range of dimensionless distance $0.5 \leq h / d \leq 8$ were presented as graphical dependencies of the measured quantities on the dimensionless radial coordinate $r / d$ and nozzle-to-plate distance $h / d$. The Nusselt number correlations in typical regions of the impinging jet - the stagnant region $0 \leq r / d \leq 1$, the transition region $1 \leq r / d \leq 2.5$ and the wall jet region $r / d>2.5$ - were presented and compared with the literature data. They stated that the Nusselt number at the stagnation point increases with the decrease of $h / d$ below 1 . This may be due to the flow acceleration below the jet for smaller $h / d$ ratio.

Katti et al. ${ }^{8}$ published a similar study of the heat transfer in an unconfined impinging jet. They focused on smaller values of the Reynolds number within range $500-8000$. The authors mentioned that the heat transfer coefficient at the stagnation point as well as its mean value over the the whole surface show very small dependency on the nozzleto-plate distance. For the mean value of the Nusselt number defined as

$$
\overline{\mathrm{Nu}}=\frac{2}{R^{2}} \int_{0}^{R} \mathrm{Nu} r \mathrm{~d} r
$$

the following correlation was presented

$$
\overline{\mathrm{Nu}}=0.11 \operatorname{Re}^{0.69} \operatorname{Pr}^{0.33}\left(\frac{h}{d}\right)^{-0.04}
$$

It is based on experimental data for $0 \leq r / d \leq 5$, $500 \leq \operatorname{Re} \leq 8000$ and $0.5 \leq h / d \leq 8$. The equation fits the experimental data within $15 \%$ interval for $91 \%$ of the data points with a standard deviation of about $9 \%$. Katti et al. ${ }^{8}$ stated that their results are roughly 
by $50 \%$ greater than the results of Martin $^{2}$ and described them by the following correlation for the range of Reynolds numbers $2000-30000$

$$
\overline{\mathrm{Nu}}=\frac{d}{R} \frac{1-1.1 d / R}{1+0.1(h / d-6) d / R} 1.36 \operatorname{Re}^{0.574} \operatorname{Pr}^{0.42}
$$

where $R$ is the upper integration limit in Eq. (2), i.e. the radius of the surface over which the mean value of the Nusselt number is averaged. The difference was explained by the measuring technique - Mar$\operatorname{tin}^{2}$ correlation was based on mass transfer experiments, whereas Katti et al. ${ }^{8}$ results were based on the infrared thermal imaging technique.

Sui et $a l .{ }^{9}$ measured the heat transfer coefficient between the stream of air leaving a small axial-flow fan (PC style) impinging an electrically heated surface. The results were presented for small distances of the fan and plate within range $0.2 \leq h / d \leq 2$ and constant value of the Reynolds number 9000 . The authors mentioned the existence of primary and secondary stagnation regions. Their size and position are mainly influenced by the size of the hub diameter which was equal to half of the outer fan diameter. This diameter had a strong impact on the position of the Nusselt number radial maximum as reported by the authors. The intensity of the tangential velocity component was not specified there (only the fan speed and its geometry).

Yang et al. ${ }^{10}$ measured the hydrodynamic characteristics and heat transfer between an annular impinging air jet and a flat surface. The flow patterns were measured by the PIV technique. The heat transfer intensity at the impinged surface was measured by the classical approach based on a plate heated by a constant heat flux and foil thermocouples monitoring the surface temperature. The impinging jet for swirling and non-swirling cases was produced by an annular nozzle with the ratio of inner and outer diameters equal to 0.5 . Short guide vanes were used to create the swirling jet. With the exit angle of the guide vanes set at $30^{\circ}$ and mentioned diameter ratio, the swirl number was calculated to be 0.45 . The measurements were done for constant value of the Reynolds number 7000, with a characteristic length (diameter) based on the difference between the inner and outer nozzle diameters, and for distance $0.5-4.1$ of the characteristic diameter. The PIV data implied that the tangential velocity component influences significantly the axial velocity profile identified by a reversed flow in the stagnation region, especially in the cases of large nozzle-plate distances. On the contrary, for the smallest relative distance 0.5 , where the substantial reversed flow exists, even with no tangential component, the axial velocity profiles are more or less similar (with a slightly smaller reversed flow in the case of swirling flow). It was concluded that for rel-

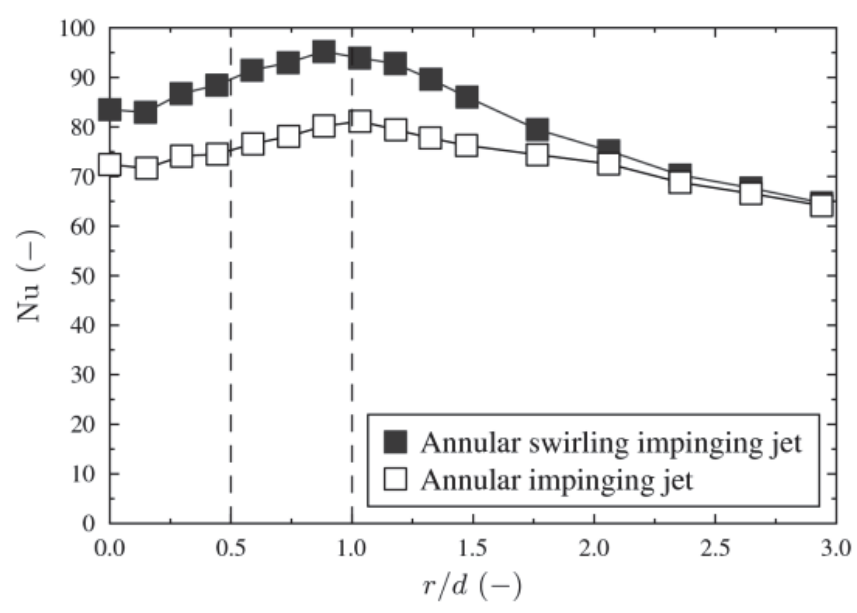

Fig. 3 - Comparison of Nusselt numbers for swirling and non-swirling annular impinging jet with relative nozzle-to-plate distance $h / d=0.5$, see Yang et al. ${ }^{10}$ for details

atively large distances $(h / d=4.1)$, the tangential velocity component decreases the heat transfer coefficients at the impinged plate in contrast to other relative distances, i.e. $2.1,1.1$ and 0.5. Figure 3 illustrates the experimental results for the smallest relative distance $h / d=0.5$.

Terekhov and Mshvidobadze ${ }^{11}$ measured heat transfer in a swirling air jet impinging a semi-spherical cavity (dimple). The Reynolds numbers of the impinging jet leaving a round nozzle were within range $10000-50000$ (flow velocities $20-100 \mathrm{~m} \mathrm{~s}^{-1}$ ), and the dimensionless distance was $0<h / d \leq 10$. A flat swirler with variable slit inclination angle was used as a geometry-type of swirl generator. The jet prerotation parameter (swirl number), defined as the momentum ratio between the circumferential component of the jet flow and the jet flow along the jet axis, was within the range 0 and 2.74. Local heat transfer coefficients and Nusselt numbers were presented with respect to the Reynolds number, swirl number, dimensionless distance (2 and 10), and radial coordinate. The heat transfer near the stagnation point decreased significantly with the increasing swirl number.

The characteristic length in the Reynolds and Nusselt dimensionless numbers in the previous correlations was represented by jet diameter $d$, that is

$$
\mathrm{Re}=\frac{U d}{v}, \quad \mathrm{Nu}=\frac{\alpha d}{\lambda}
$$

In this study of the confined swirling impinging jet depicted in Figure 1, the impinging jet with mean velocity $U$ is generated by an impeller of diameter $d_{M}$ and rotational speed $N$. It is placed in a draft tube of inner diameter $d$. The amount of liquid $Q$ pumped by the axial-flow impeller can be expressed as dimensionless pumping capacity of the impeller $\mathrm{N}_{Q}$, and along with the Reynolds number 
characterizing the flow intensity generated by the impeller

$$
\mathrm{N}_{Q}=\frac{Q}{N d_{M}^{3}}, \quad \operatorname{Re}_{M}=\frac{N d_{M}^{2}}{v}
$$

they can be used to derive the following relation between the Reynolds number $\mathrm{Re}_{M}$ for a mixing system and the Reynolds number Re for a jet

$$
\operatorname{Re}_{M}=\operatorname{Re} \frac{\pi}{4} \frac{d}{d_{M}} \frac{1}{\mathrm{~N}_{Q}}
$$

Here, the characteristic length of the jet Reynolds number (5) is inner diameter $d$ of the draft tube.

The value of dimensionless pumping capacity depends on the geometry of the vessel, draft tube, and impeller. Vlček and Jirout ${ }^{1}$ performed numerical simulations of flow in a vessel with a draft tube, and they determined the pumping capacities for parameters summarized in Table 1. Using Equations (5) and (7), the ratio of the tangential and axial velocity components can be expressed

$$
\frac{W}{U}=\frac{\pi^{2}}{4}\left(\frac{d}{d_{M}}\right)^{2} \frac{W^{*}}{\mathrm{~N}_{Q}}, W^{*}=\frac{W}{\pi d_{M} N}
$$

where $W^{*}$ is the dimensionless maximum tangential velocity at the outlet of the draft tube which is also depicted in Figure 1. $W$ is the maximum tangential velocity component at the outlet of the draft tube.

The relation between the tangential and axial velocity components can be expressed also in terms of swirl number $S$ introduced by Chigier and Beer ${ }^{12}$

$$
S=\frac{2}{d} \frac{G_{w}}{G_{u}}, G_{w}=\int_{A} \rho r w u \mathrm{~d} A, G_{u}=\int_{A} \rho u^{2} \mathrm{~d} A
$$

where $G_{w}$ and $G_{u}$ represent axial fluxes of tangential and axial momentums, respectively. $A$ refers here to the outlet cross-section area of the draft tube. In the case of constant velocity profiles with axial and tangential components $U$ and $W$, swirl number can be derived as

$$
\mathrm{S}=\frac{2}{3} \frac{W}{U}
$$

In the case of the studied geometry, the real axial and tangential velocity components at the draft tube outlet are depicted in Figure 1 (in a dimensionless form). Approximating these velocity profiles by straight lines with maximum values at the radius of the draft tube (and zeros at the center), the swirl number can be expressed as

$$
\mathrm{S}=\frac{8}{15} \frac{\mathrm{W}}{U}
$$

where $W$ is the maximum tangential velocity component and $U$ is the bulk (mean) velocity in the ax- ial direction. Their ratio is defined by Eq. (8) and depends on the pumping capacity of the impeller which is a function of its rotation rate.

\section{Experimental}

Frequently used experimental technique in heat transfer measurements is based on the analogy between heat and mass transfer which forms the basis of the electrodiffusion (electrochemical) method. The similarity of transport equations describing the heat and mass transport yields the relation between dimensionless Nusselt and Sherwood numbers, which can be used to determine heat transfer coefficients. The electrodiffusion method measures the limiting diffusion current between the small working electrode and the large electrode (so that polarization effects on the large electrode can be neglected). Assuming the zero concentration of active electrolyte (potassium ferri/ferrocyanide aqueous solution is frequently used) on the working electrode, the molar flux at the electrode surface $A$ can be expressed as $I / z F A=k c_{\infty}$, where $I$ is the limiting diffusion current, $z$ is the number of electrons involved in the electrochemical reaction, $c_{\infty}$ is molar concentration of the active component in the electrolyte, $k$ is the mass transfer coefficient, and $F$ is the Faraday constant. The mass transfer coefficient can be then used to express the Sherwood number $\mathrm{Sh}=k d / D_{A B}\left(D_{A B}\right.$ is diffusion coefficient of the active component), and consequently the heat transfer coefficient $\alpha_{\mathrm{EDD}}$ on the basis of the heatmass transfer analogy can be evaluated.

$$
\alpha_{\mathrm{EDD}}=\rho c_{\mathrm{P}}\left(\frac{\mathrm{Sc}}{\mathrm{Pr}}\right)^{2 / 3} \frac{I}{z} F A c_{\infty}
$$

The geometrical configurations as well as the boundary conditions should be similar when using the electrodiffusion method. But it is difficult to satisfy the similarity of boundary conditions in the case of small electrodes because the width of the thermal boundary layer differs from the real case of heat (mass) transfer at the whole surface. This difference can be taken into account by correction factor $p$, defined as the ratio of real heat transfer coefficient $\alpha$ and heat transfer coefficient $\alpha_{\mathrm{EDD}}$ measured by the electrodiffusion method with small electrodes, i. e. $p=\alpha / \alpha_{\mathrm{EDD}}$. Detailed description of the electrodiffusion method and how to resolve issues with measurements on small electrodes can be found in papers ${ }^{13,14}$. Results of numerical simulations of heat transfer on small electrodes of $0.5 \mathrm{~mm}$ and $4 \mathrm{~mm}$ diameters and graphical dependencies of correction factor $p$ are stated in paper ${ }^{13}$.

The electrochemical method with small electrodes measured the distribution of local heat trans- 
fer coefficients on a flat bottom of an agitated vessel with diameter $D=392 \mathrm{~mm}$. We used axial six-blade impellers with three different pitched angles $30^{\circ}, 45^{\circ}, 60^{\circ}$ and diameter $d_{M}=61 \mathrm{~mm}$ situated inside a draft tube with inner diameter $d=70 \mathrm{~mm}$. The draft tube was positioned 70,35 and $17.5 \mathrm{~mm}$ above the vessel bottom $(h / d=1,0.5$ and 0.25$)$ and produced a stream jet similar to the impinging jet with additional tangential (swirling) velocity component. The height $H$ of liquid (electrolyte) was $430 \mathrm{~mm}$ above the bottom. Twelve small platinum electrodes of $0.5 \mathrm{~mm}$ diameter were uniformly positioned in the radial direction at the vessel bottom. As the electrolyte, $20 \mathrm{~mol} \mathrm{~m}^{-3}$ equimolar potassium ferri/ferrocyanide aqueous solution supplemented by $1.5 \%$ mass $\mathrm{K}_{2} \mathrm{SO}_{4}$ was used. The density of this solution was $1018 \mathrm{~kg} \mathrm{~m}^{-3}$, kinematic viscosity $1.065 \cdot 10^{-6} \mathrm{~m}^{2} \mathrm{~s}^{-1}$ and diffusivity $7.5 \cdot 10^{-10} \mathrm{~m}^{2} \mathrm{~s}^{-1}$ at temperature $20^{\circ} \mathrm{C}$ (constant temperature $\pm 0.1^{\circ} \mathrm{C}$ was maintained in the experiment). ${ }^{15}$ Properties of distilled water were used in place of other necessary properties in the calculations. The number of electrons involved in this electrochemical reaction was assumed to be equal to 1 . Polarization potential $0.8 \mathrm{~V}$ was used and verified by the linear sweep voltammetry. Measurements were performed at constant impeller rotation speeds $N$. The limiting diffusion current was measured with frequency $100 \mathrm{~Hz}$ on all working electrodes during $120 \mathrm{~s}$ time period. The time-averaged value of the diffusion current was then used in evaluation of the local heat transfer coefficients.

Figure 4 shows typical radial profiles of the evaluated Nusselt numbers for some of the analyzed geometrical configurations.

A regression analysis of the measured Nusselt numbers based on the least-squares method and the following model function

$$
\mathrm{Nu}=c \operatorname{Re}^{n}
$$

will give power $n$ of the Reynolds number. The values of $n$ represent characteristics of the flow in a corresponding location, and their radial profiles for some geometrical configurations are depicted on Figure 5. It shows clearly that the Reynolds power is around 0.5 in the stagnation region which is a frequently used value coming from experimental data or theoretical solution near the stagnation point of a pure impinging jet (with no tangential component). Moving away from the stagnation point, the value of 0.7 is approached which is typical for transitional and wall jet regions.

Figure 6 compares local values of the Nusselt number for individual dimensionless distances $h / d=1$ and 0.25 . They are based on the measured Nusselt numbers and same Reynolds number 11000 , so that the influence of individual parameters could
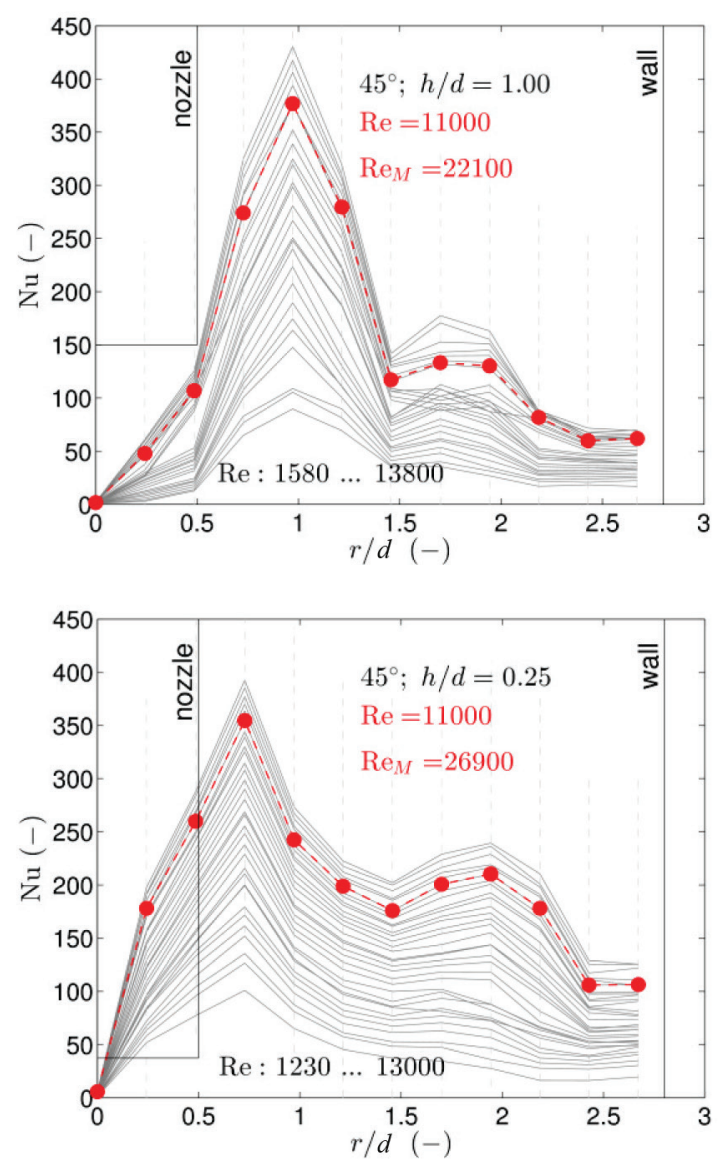

Fig. 4 -Evaluated Nusselt number values and their dependencies on dimensionless radial coordinate $r / d$ for some of the analyzed geometrical configurations. The filled circles connected with dashed lines emphasize interpolated values of the Nusselt number for Reynolds number 11000.

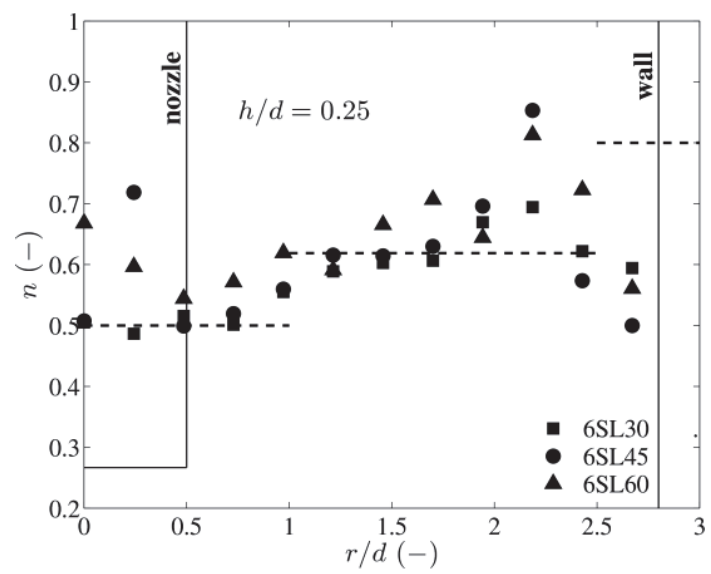

Fig. 5 - Reynolds power $n$ in correlation for the Nusselt number (13) and its dependency on dimensionless radial coordinate $r / d$ for $h / d=0.25$ and three different pitched angles, $30^{\circ}, 45^{\circ}$, and $60^{\circ}$

be interpreted. The effect of the tangential velocity component is more visible with smaller distances from the vessel bottom, and it is very small for dimensionless distance $h / d=1$. 

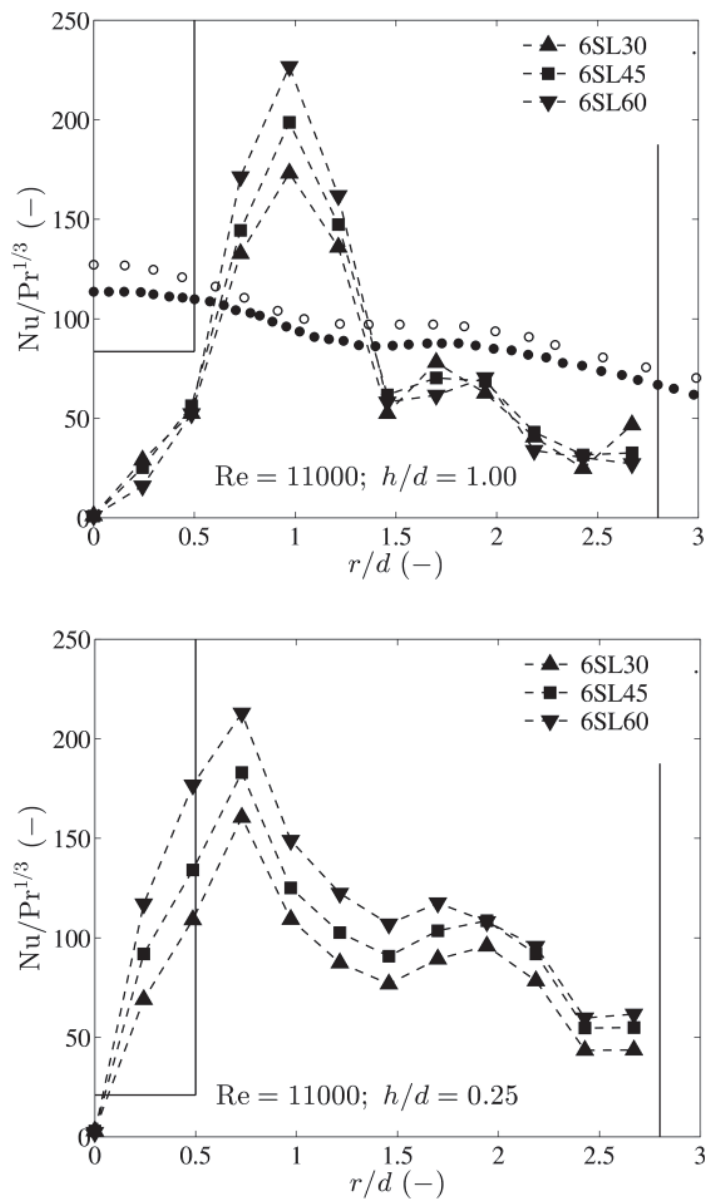

Fig. 6 - Experimental values of the Nusselt numbers with respect to the dimensionless radial coordinate r/d for Reynolds number $11000, h / d=1$, and $h / d=0.25$. For comparison, filled circles represent experimental data ${ }^{4}$ in an unconfined impinging jet with no tangential component for Reynolds number 12000 , and empty circles represent data for $R e=11000$.

Table 1 - Dimensionless pumping capacities $N_{O}$, maximum dimensionless tangential velocities $W^{*}$ at the outlet of the draft tube, and corresponding dimensionless radial position $r^{*}=r \mid W^{*} / d$ for several geometrical parameters of the impeller and draft tube. A mesh with $6 \cdot 10^{5}$ elements was used in numerical simulations ${ }^{l}$ and a comparison with dimensionless pumping capacities gained on a mesh with $2 \cdot 10^{6}$ elements gives error estimation $15 \%$

\begin{tabular}{c|c|c|c|c}
\hline $\begin{array}{c}\text { Pitched } \\
\text { angle }\end{array}$ & $h / d$ & $\mathrm{~N}_{Q}$ & $W^{*}$ & $r^{*}$ \\
\hline $30^{\circ}$ & 1.0 & 0.381 & 0.1379 & 0.89 \\
& 0.5 & 0.368 & 0.1315 & 0.86 \\
& 0.25 & 0.332 & 0.1389 & 0.91 \\
\hline $45^{\circ}$ & 1.0 & 0.449 & 0.1817 & 0.89 \\
& 0.5 & 0.423 & 0.1786 & 0.92 \\
& 0.25 & 0.369 & 0.1789 & 0.91 \\
\hline $60^{\circ}$ & 1.0 & 0.437 & 0.2099 & 0.89 \\
& 0.5 & 0.410 & 0.2015 & 0.89 \\
& 0.25 & 0.356 & 0.2180 & 0.89 \\
\hline
\end{tabular}

The Reynolds numbers were evaluated according to Eqs. (5-7) using corresponding dimensionless pumping capacities $\mathrm{N}_{O}$ for the measured configurations summarized in Table 1.

\section{Results and discussion}

The tangential velocity component superposed on the main axial velocity component has a significant impact on the heat transfer intensity in a impinging jet. Some authors describe the influence of the tangential velocity component by the swirl number, see Eq. (9), and other authors use a modified Reynolds number defined with a characteristic velocity in the tangential direction (which could be a questionable definition). Swirl number $S$ is usually incorporated into a correlation describing the Nusselt number, as in the following equation

$$
\mathrm{Nu}=c \operatorname{Re}^{n} \operatorname{Pr}^{r}\left(\frac{h}{d}\right)^{s} S^{t}
$$

where power $1 / 3$ (or 0.4 ) is used with the Prandtl number.

On the basis of all measured Nusselt numbers the following correlation for the mean Nusselt number defined by Eq. (2) can be expressed in terms of the Reynolds number, dimensionless distance of the draft tube from the vessel bottom $h / d$, and swirl number $S$

$$
\overline{\mathrm{Nu}}=0.041 \operatorname{Re}^{0.826} \operatorname{Pr}^{1 / 3}\left(\frac{h}{d}\right)^{-0.099} S^{0.609}
$$

The swirl number is described here by Eq. (11). The integration limit is given by the outer diameter of the vessel, $0 \leq r / d \leq 2.67$, and the valid range of dimensionless distance is $0.25 \leq h / d \leq 1$. The confidence intervals of individual parameters determined in the non-linear least-squares regression analysis are as follows

$$
\begin{aligned}
& 0.041 \pm 0.005,0.826 \pm 0.013, \\
& -0.099 \pm 0.010,0.609 \pm 0.036
\end{aligned}
$$

Figure 7 compares the correlation for the mean (average) Nusselt number described by Eq. (15) with the measured data and literature correlations for unconfined impinging jets with no tangential velocity component by Katti et al. ${ }^{8}$ (integration limit $0 \leq r / d \leq 5)$, Lytle and $\mathrm{Webb}^{4}(0 \leq r / d \leq 2)$, and Mar$\operatorname{tin}^{2}(0 \leq r / d \leq 2.67)$. The mean values are evaluated for circular surface limited by the radius of the outermost probe (it is $187 \mathrm{~mm}$ which is $95.4 \%$ of the vessel diameter $196 \mathrm{~mm}$ in our case). Deviations of the mean Nusselt numbers based on the experimental data from the Nusselt numbers described by correlation (15) mentioned above are depicted on the 

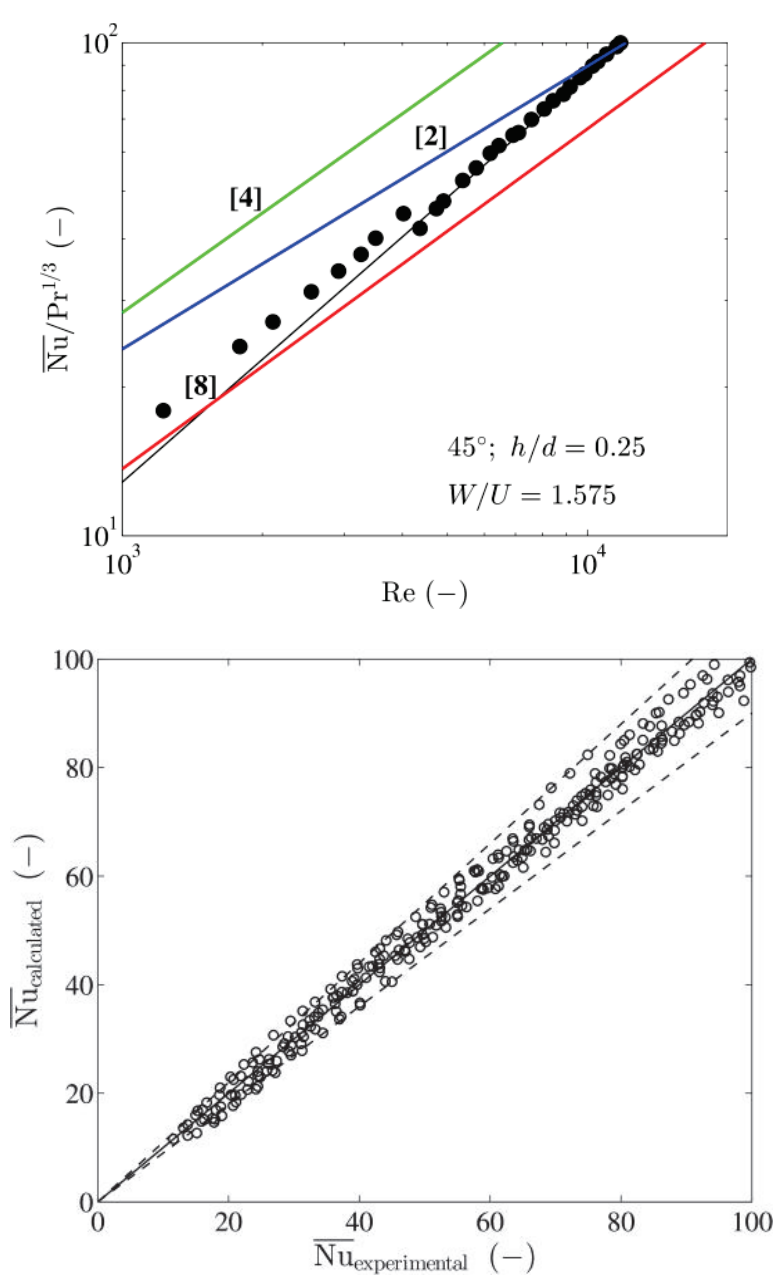

Fig. 7 - On the top, the proposed correlation (15) and the measured data (for pitched angle $45^{\circ}$ and $h / d=0.25$ only) are compared with literature correlations Katti et al. ${ }^{8}$ (line [8], integration limit $0 \leq r / d \leq 5$ ), Lytle and $\mathrm{Webb}^{4}$ (line [4], $0 \leq r / d \leq 2$ ), and Martin ${ }^{2}$ (line [2], $0 \leq r / d \leq 2.67$ ). On the bottom, the mean Nusselt number values based on the experimental data are compared with values evaluated from correlation (15), integration limit $0 \leq r / d \leq 2.67$. Relative error $\pm 10 \%$ is delimited by the two spreading dashed lines.

bottom side of Figure 7. Most of the experimental points lie in a band representing relative error $\pm 10 \%$.

The influence of a substantial tangential velocity component is demonstrated in Figure 6. The centrifugal forces increase the radial flow in the stagnation region with an extensive impact on the axial velocity profile - the axial velocity drops nearly to zero at the center, and a large peak in the heat transfer intensity (Nusselt number) appears near $r / d=1$. The centrifugal forces are dampened by viscous forces with increasing radius where the heat transfer is comparable with values in an unconfined impinging jet with no tangential component. Near the wall of the confined geometry (vessel), the change of flow direction results in another substantial drop in heat transfer intensity when compared to a standard unconfined impinging jet. Here, it has much larger impact on the mean value of the Nusselt number over the whole surface because the corresponding surface integrated in Equation (4) is relatively large (in contrast to the center where the influence of small heat transfer intensities is relatively small). In summary, despite the additional tangential velocity component, the mean value of the Nusselt number at the bottom of an agitated vessel impinged by a swirling flow generated by an impeller is smaller than the Nusselt number in an unconfined impinging jet with comparable axial-flow Reynolds number and no tangential velocity component.

\section{Conclusions}

The influence of tangential velocity component on the heat transfer at the bottom of a cylindrical vessel impinged by a flow generated by an axial-flow impeller was investigated in this paper. The electrodiffusion method was used to measure the local values of heat transfer coefficients at the vessel bottom. A correlation describing the mean Nusselt number at the vessel bottom in terms of the Reynolds number, Prandtl number, dimensionless distance and swirl number is proposed. A comparison of experimental data gained by the electrodiffusion method (verified independently by the TOIRT method) with literature experimental data for unconfined impinging jets showed that the mean Nusselt number values are smaller in a flow with the additional tangential (swirling) velocity than in an unconfined impinging jet. The main reason lies in a different axial velocity profile, which develops at the outlet of the draft tube due to the tangential velocity component and consequent centrifugal forces.

The experimental results were independently verified by a contactless (infrared) temperature-oscillations method (TOIRT) introduced by Wandelt and Roetzel ${ }^{16}$ and used by Freund et al. ${ }^{17}$ Local values of the heat transfer coefficients at the whole heat transfer surface can be determined with this method, and consequently their mean values along the radial coordinate can be evaluated. Very good agreement of the position and magnitude of the heat transfer maximum was obtained with this method (maximum deviation $10 \%$ ). Larger differences of this method are visible near the stagnation point, however this region has relatively small impact on the resulting mean values over the whole surface because it is represented by relatively small surface. Experimental results of the electrodiffusion method used in this paper compared with the TOIRT method $^{16}$ were found to be within interval $\pm 15 \%$ in the turbulent flow regime. 


\section{ACKNOWLEDGEMENT}

This work has been supported by research project of the Grant Agency of Czech Republic No. 14-18955S.

\section{Nomenclature}

$c_{\mathrm{P}} \quad-$ specific heat capacity, $\mathrm{J} \mathrm{kg}^{-1} \mathrm{~K}^{-1}$

$c_{\infty} \quad-$ molar concentration of active component, $\mathrm{mol} \mathrm{m}{ }^{-3}$

$d \quad-$ jet nozzle diameter, draft tube diameter, $\mathrm{m}$

$d_{M} \quad-$ impeller diameter, $\mathrm{m}$

$D \quad$ - vessel diameter, $\mathrm{m}$

$D_{A B} \quad$ - diffusion coefficient of active component, $\mathrm{m}^{2} \mathrm{~s}^{-1}$

$\mathrm{F} \quad-$ Faraday constant, $\mathrm{C} \mathrm{mol}^{-1}$

$G_{u} \quad-$ axial flux of axial momentum, Eq. (9), $\mathrm{kg} \mathrm{\textrm {m } \mathrm { s } ^ { - 2 }}$

$G_{w} \quad-$ axial flux of tangential momentum, Eq. (9), $\mathrm{kg} \mathrm{m}^{2} \mathrm{~s}^{-2}$

$h \quad-$ distance of nozzle (draft tube) outlet from impinged plate (bottom), $\mathrm{m}$

$H \quad$ - fluid level above bottom, m

I $\quad-$ limiting diffusion current, A

$k \quad-$ mass transfer coefficient, $\mathrm{m} \mathrm{s}^{-1}$

$n \quad-$ general constant, Reynolds number exponent, -

$N \quad$ - rotational speed of impeller, $\mathrm{s}^{-1}$

$\mathrm{Nu} \quad-$ Nusselt number, Eq. (5), -

$\overline{\mathrm{Nu}} \quad-$ mean (average) Nusselt number for $r \in\langle 0, R\rangle,-$

$\mathrm{Nu}_{0} \quad-$ Nusselt number at stagnant point, -

$\mathrm{N}_{Q} \quad-$ dimensionless pumping capacity of impeller, Eq. (6), -

$p$

- correction factor of heat transfer coefficient, -

Pr $\quad-$ Prandtl number, $\operatorname{Pr}=v / a,-$

$Q \quad$ - pumping capacity of impeller, volumetric flow rate through impeller, $\mathrm{m}^{3} \mathrm{~s}^{-1}$

$r \quad-$ radial coordinate, $\mathrm{m}$

$r^{*} \quad-$ dimensionless radial coordinate, -

$R \quad$ - radius, $\mathrm{m}$

Re $\quad-$ Reynolds number, Eq. (5), -

$\mathrm{Re}_{M} \quad-$ mixing Reynolds number, Eq. (6), -

$S$

$\mathrm{Sc}$

$\mathrm{Sh}$

$t$ $u$

$U$

- bulk velocity (average velocity at the jet nozzle), $\mathrm{m} \mathrm{s}^{-1}$

w $\quad-$ tangential velocity, $\mathrm{m} \mathrm{s}^{-1}$

$w^{*} \quad-$ dimensionless tangential velocity, -

$W \quad-$ maximum tangential velocity, $\mathrm{m} \mathrm{s}^{-1}$

$W^{*} \quad-$ dimensionless maximum tangential velocity, Eq. (8), -

$z-$ number of electrons involved in electrochemical reaction, -

- heat transfer coefficient, $\mathrm{W} \mathrm{m}^{-2} \mathrm{~K}^{-1}$

$\alpha_{-}-$heat transfer coefficient based on electrochemical measurement, $\mathrm{W} \mathrm{m}^{-2} \mathrm{~K}^{-1}$

$\lambda-$ thermal conductivity, $\mathrm{W} \mathrm{m}^{-1} \mathrm{~K}^{-1}$

$\mu \quad-$ dynamic viscosity, $\mathrm{Pa} \mathrm{s}$

$v \quad-$ kinematic viscosity, $v=\mu / \rho, \mathrm{m}^{2} \mathrm{~s}^{-1}$

$\rho \quad-$ density, $\mathrm{kg} \mathrm{m}^{-3}$

\section{References}

1. Vlček, P., Jirout, T., CFD simulation of flow in mixing equipment with draft tube, CHISA conference, Seč, Czech Republic, 2015.

2. Martin, H., Heat and Mass Transfer between Impinging Gas Jets and Solid Surfaces, Advances in heat transfer, Vol. 13, Academic Press, New York, 1977, pp 1-60. doi: https://doi.org/10.1016/S0065-2717(08)70221-1

3. Lytle, D., Webb, B. W., Secondary maxima for air jet impingement at low nozzle-to-plate spacings, in: R. S. Keffer, J. F., Gánic, E. (Eds.), Proceedings Second World Conference on Experimental Heat Transfer, Fluid Mechanics, and Thermodynamics, 1991, pp 776-783.

4. Lytle, D., Webb, B., Air jet impingement heat transfer at low nozzle-plate spacings, Int. J. of Heat Mass Transfer 37 (1994) 1687. doi: https://doi.org/10.1016/0017-9310(94)90059-0

5. Viskanta, R., Heat transfer to impinging isothermal gas and flame jets, Experimental Thermal and Fluid Sci. 6 (1993) 111. doi: https://doi.org/10.1016/0894-1777(93)90022-B

6. Sun, H., Ma, C. F., Tian, Y. Q., Local convective heat transfer from small heaters to impinging submerged axisymmetric jets of seven coolants with Prandtl number ranging from 0.7 to 348, J. Thermal Science 6 (1997) 286. doi: https://doi.org/10.1007/s11630-997-0008-3

7. Katti, V., Prabhu, S., Experimental study and theoretical analysis of local heat transfer distribution between smooth flat surface and impinging air jet from a circular straight pipe nozzle, Int. J. Heat Mass Transfer 51 (2008) 4480. doi: https://doi.org/10.1016/j.ijheatmasstransfer.2007.12.024

8. Katti, V. V., Yasaswy, S. N., Prabhu, S. V., Local heat transfer distribution between smooth flat surface and impinging air jet from a circular nozzle at low Reynolds numbers, Heat and Mass Transfer 47 (2011) 237. doi: https://doi.org/10.2514/6.2008-5727

9. Sui, D., Kim, T., Xu, M. L., Lu, T. J., Flow and heat transfer characteristics of impinging axial fan flows on a uniformly heated flat plate, Int. J. Trans. Phenomena 10 (2008) 353. 
10. Yang, H. Q., Kim, T. B., Lu, T. J., Characteristics of annular impinging jets with/without swirling flow by short guide vanes, Technol. Sci. 54 (2011) 749. doi: https://doi.org/10.1007/s11431-010-4233-8

11. Terekhov, V. I., Mshvidobadze, Y. M., Features of heat transfer at interaction of an impact swirl jet with a dimple, Thermal Sci. 20 (2016) S35.

doi: https://doi.org/10.2298/TSCI150819137T

12. Chigier, N. A., Beer, J. M., Velocity and static-pressure distributions in swirling air jets issuing from annular and divergent nozzles, Trans. ASME 86D, Journal of Basic Engineering 4 (1964) 788.

doi: https://doi.org/10.1115/1.3655954

13. Petera, K., Dostál, M., Jirout, T., Fořt, I., Heat transfer similarities between impinging jets and axial-flow impellers, Theor. Found. Chem. Eng. 50 (2016) 937. doi: https://doi.org/10.1134/S0040579516060130
14. Karcz, J., Studies of local heat transfer in a gas-liquid system agitated by double disc turbines in a slender vessel, Chem. Eng. J. 72 (1999) 217. doi: https://doi.org/10.1016/s1385-8947(99)00005-4

15. Kristiawan, M., Meslem, A., Nastase, I., Sobolik, V., Wall shear rates and mass transfer in impinging jets: Comparison of circular convergent and cross-shaped orifice nozzles, Int. J. Heat Mass Transfer 55 (2012) 282. doi: https://doi.org/10.1016/j.ijheatmasstransfer.2011.09.014

16. Wandelt, M., Roetzel, W., Lockin thermography as a measurement technique in heat transfer, QIRT 96 - Eurotherm Series 50, 1997, pp 189-194. doi: https://doi.org/10.21611/qirt.1996.031

17. Freund, S., Pautsch, A. G., Shedd, T. A., Kabelac, S., Local heat transfer coefficients in spray cooling systems measured with temperature oscillation IR thermography, Int. J. Heat Mass Transfer 50 (2007) 1953. doi: https://doi.org/10.1016/j.ijheatmasstransfer.2006.09.028 